\title{
State-of-the-art modalities
}

\section{in cardio-oncology: insight from a nuclear medicine approach}

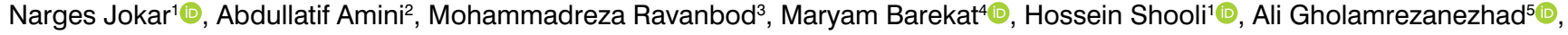 \\ Majid Assadi ${ }^{10}$ \\ ${ }^{1}$ The Persian Gulf Nuclear Medicine Research Center, Department of Molecular Imaging and Radionuclide Therapy (MIRT), Bushehr \\ Medical University Hospital, Bushehr University of Medical Sciences, Bushehr, Iran \\ ${ }^{2}$ Medical Heart Center, Faculty of Medicine, Bushehr University of Medical Sciences, Bushehr, Iran \\ ${ }^{3}$ Department of Internal Medicine, Persian Gulf Tropical Medicine Research Center, Bushehr University of Medical Sciences, Bushehr, Iran \\ ${ }^{4}$ Department of Regenerative Medicine, Cell Science Research Center, Royan Institute for Stem Cell Biology and Technology, ACECR, \\ Tehran, Iran
}

${ }^{5}$ Department of Radiology, Keck School of Medicine, University of Southern California, Los Angeles, United States

[Received 19 XI 2020; Accepted 16 III 2021]

\begin{abstract}
Cancer and cardiovascular disease are the most significant causes of morbidity and mortality worldwide. Although the cancer survival rate has increased due to improved treatment approaches, especially targeted therapy, some side effects such as cardiotoxicity decrease the efficiency of the clinical outcome. Radiation therapy and chemotherapy have a long-established history of potential cardiotoxic effects. A new multi-disciplinary and translational field known as cardio-oncology has been developed for the identification, prevention, and treatment of cardiovascular dysfunctions associated with cancer treatment approaches. One of the important tools for detecting and monitoring cardiotoxic effects is non-invasive nuclear cardiac imaging techniques. Cardiac nuclear imaging modalities especially recent findings positron emission tomography (PET) tracers have a quintessential role in the early detection of cardiovascular disorders. Moreover, comprehensive studies are required to investigate novel nuclear medicine treatment approaches such as peptide receptor radionuclide therapy (PRRT), fibroblast activation protein (FAP), and chemokine receptor (CXCR) targeting probes for possible cardiac side effects that play important roles in the treatment of malignancies.
\end{abstract}

KEY words: cardiotoxicity; cardio-oncology; PRRT-related cardiotoxicity; nuclear medicine; FAPI; CXCR4; [99mTc]Sestamibi; $\left[{ }^{18} \mathrm{~F}\right]$ MitoPhos; $\left[{ }^{68} \mathrm{Ga}\right]$ Galmydar

Nucl Med Rev 2021; 24, 2: 82-92

\section{Background}

Cancer and cardiovascular disease are the most significant causes of morbidity and mortality worldwide [1]. Significant advances have been made in the early detection, treatment, and long-term survival of cancer patients. Importantly, each new therapeutic development has encountered specific challenges such as multi-organ adverse events [2]. Therefore, cardiovascular

Correspondence to: Majid Assadi

The Persian Gulf Nuclear Medicine Research Center, Department of Molecular Imaging and Radionuclide Therapy (MIRT), Bushehr Medical

University Hospital, Bushehr University

of Medical Sciences, 45654775 Bushehr, Iran

e-mail: assadipoya@yahoo.com diseases and malignancies may coexist in these patients because of using combination treatment approaches in molecular oncology for better patient management [3]

Cardiotoxicity as acute and occasionally lethal cardiac events (chronic) related to cancer therapeutic methods occurs either during or immediately following treatment in patients exposed to mediastinal radiation therapy (RT) and anti-cancer drugs as well as decreases the efficiency of the patient's health outcomes. It is categorized into different subtypes (Type I and II) including cardiomyopathy, thrombosis, hypertension, left ventricular dysfunction, QT prolongation, oedema, arrhythmias, metabolic abnormalities, and capillary leak syndrome, which might lead to cardiovascular abnormalities, especially in elderly patients with pre-existing cardiovascular disease [4-9]. Some chemotherapy agents such as vinblastine, anthracyclines, ramucirumab, 
trastuzumab, cyclophosphamide, and 5-fluorouracil, can increase the risk of cardiovascular diseases in patients with different malignancies (breast, sarcoma, lung, bladder, gastric, prostate, leukaemia, lymphoma, etc.) [10]. Moreover, there are different reasons for radiation-induced cardiovascular dysfunction such as damage to cardiomyocytes as well as stimulating an inflammatory process in cardiac cells leading to the acceleration of atherosclerosis [11].

Cardio-oncology is a multidisciplinary clinical approach that improves awareness of monitoring and treatment methods in patients with cardiovascular complications related to cancer treatment [12]. According to The American Society of Echocardiography and the European Association of Cardiovascular Imaging, cardiotoxicity defines as a $10-15 \%$ early reduction in global longitudinal strain index [13].

One of the important tools for early detection and monitoring cardiotoxic effects are non-invasive imaging techniques. These techniques also give opportunities for the classification of therapeutic choices to improve patient management. Among these techniques, cardiac nuclear imaging modalities including planar multi-gated acquisition or multi-gated radionuclide angiography (MUGA), single-photon emission computed tomography (SPECT), and PET scans have demonstrated a significant role in the detection, screening during treatment, and monitoring of cancer treatment-related cardiotoxicities [14, 15].

Heretofore, chemotherapeutic agents were extensively assessed for cancer-therapy-related cardiotoxicity $[9,16]$. On the other hand, recent developments in the field of nuclear medicine resulting in the introduction of new treatment modalities along with other common approaches require extensive investigations for probable side effects, including cardiotoxicity.

In this state-of-the-art review, the authors briefly present cancer treatment techniques that may induce cardiotoxicity and discuss nuclear cardiac imaging modalities used for detecting cardiotoxicity related to cancer treatment. New treatment modalities in the field of nuclear medicine are also evaluated in terms of potential cardiotoxic effects.

\section{Cancer treatment approaches inducing cardiotoxicity}

One of the unexpected adverse events of mediastinal RT is cardiotoxicity. The most important risk factors for radiation-associated heart failure include a delivered dose of more than 30-35 Gray (Gy), hyper-fractionated regimens including multiple dose fractions per day, exposure of an extensive volume of the heart to radiation, younger age, long-term survival, and some other patient characteristics such as obesity, family history of heart problems, diabetes, inactive lifestyle, dyslipidaemias, hypertension, and smoking [17]. Radiation-induced heart disease commonly occurs in patients with Hodgkin lymphoma, lung cancer, and breast cancer involving cardiac structures [18]. For many years, Hodgkin lymphoma patients used a traditional radiation therapy technique, known as the mantle technique, that induced cardiac disease and cardiotoxicity [19]. However, more developments resulted in less cardiac exposure to ionizing radiation, but cardiotoxicity remains a major concern in Hodgkin lymphoma [20]. Moreover, radiation therapy, as an adjuvant or neoadjuvant technique, has been used in more than $50 \%$ of patients with breast cancer. In a meta-analysis carried out in 2005 , the researchers found that cardiovascular-related mortality increased significantly (27\%) in patients with combined treatment modalities including surgery and radiation therapy versus surgery as the only treatment modality [21]. Advanced modalities of high-precision RT techniques including intensity-modulated radiotherapy (IMRT), volumetric modulated arc therapy (VMAT), helical tomotherapy, prone and isocentric lateral decubitus (ILD) positions, breath-hold techniques, and proton therapy result in dose homogeneity, less cardiac exposure, and delivering lower doses to the heart and reduce adverse effects. The suitable selection of these techniques (alone or in combination) is based on the patient's characteristics, RT regions, and accessibility [22-33]. Although long-term follow-ups are needed to confirm the definitive role of these new techniques, clinical findings have been confirmed the positive effects of new radiation therapy techniques resulting in more precise treatment plans and decreased life-threatening effects including cardiotoxicity [34, 35].

Additionally, cardiac dysfunctions occur in a significant proportion of patients who receive chemotherapy. The pathophysiology of chemotherapeutic drug-induced cardiotoxicity is complex that involves multiple biochemical pathways and results in considerable efforts that have been made for early detection of cardiotoxic events. The most common drug classes that induce cardiotoxicity are anthracyclines (such as doxorubicin), alkaline agents (such as cyclophosphamide, ifosfamide), antimetabolite agents (such as 5-Fluorouracil (5-FU), and vinblastine [36]. Cardiac abnormalities mostly reduce left ventricular ejection fraction (LVEF) in more than $20 \%$ of the patients, which may not be detected until the final chemotherapy session [37, 38].

Monoclonal antibodies were developed as a basis for biological therapeutics for many cancers by Kohler and Milstein [39]. The main strategy of these drugs is anti-angiogenic treatment methods involving many factors such as vascular endothelial growth factor (VEGF). Bevacizumab, trastuzumab, ramucirumab, interleukin-2 (IL-2), and interferon-Alpha (INF) are the most common biological treatment agents for cancer patients that may cause cardiovascular toxicity (Tab. 1) [36, 40-43]. Some studies reported significant cardiotoxicity induced by bevacizumab in patients with breast cancer, renal cell carcinoma, and glioma [44-47]. Trastuzumab regimen is another monoclonal antibody that blocks the human epidermal growth factor receptor-2 (HER2 or ErbB2) in breast and gastric cancers including HER-2 positive receptors. In addition to improved disease-free survival, this drug induces acute cardiac disorders such as congestive heart failure and LV dysfunction as well as result in partial impairment in mitochondrial function and increased levels of oxidative stress (Fig. 1) [43, 48, 49].

Systematic studies and evidence-based recommendations are required to determine the early biomarkers of toxicity, risk-assessment models, monitoring, survivorship, prognostication of cardiotoxicity, and suitable treatment options for elderly people with malignancy that receive potentially cardiotoxic regimens.

Specifically, non-invasive and cost-effective diagnostic tools such as imaging have a high priority in detecting early cardiovascular disorders and play an important role in risk stratification and accurate management of elderly patients with cancer. 
Table 1. Common anticancer agents with potential cardiotoxicity

\begin{tabular}{|c|c|c|c|}
\hline Agent & Drug class & Cancer clinical use & Type of cardiotoxicity \\
\hline Doxorubicin & Anthracyclines (Chemotherapeutic agent) & $\begin{array}{l}\text { Breast, sarcoma, lung, bladder, gastric, } \\
\text { prostate, leukemia, lymphoma, others }\end{array}$ & LV dysfunction \\
\hline Cyclophosphamide & Alkylating (Chemotherapeutic agent) & Sarcoma, SCT, Iymphoma, myeloma, breast & Myopericarditis, arrhythmias \\
\hline Ifosfamide & Alkylating (Chemotherapeutic agent) & Testicular, sarcoma, lymphoma & Arrhythmias, LV dysfunction \\
\hline 5-Fluorouracil (5-FU) & Antimetabolites (Chemotherapeutic agent) & Colon, pancreatic, breast, head and neck & Coronary vasospasm, ischemia, arrhythmias \\
\hline Vinblastine & Antimicrotubule (Chemotherapeutic agent) & Lymphoma, testicular, lung, melanoma & $\begin{array}{l}\text { Ischemia, } \\
\text { hypertension }\end{array}$ \\
\hline Bevacizumab & Antibody VEGF (Biologic agents) & $\begin{array}{l}\text { Colon, rectal, cervical, glioblastoma, } \\
\text { ovarian, renal, endometrial, sarcoma }\end{array}$ & $\begin{array}{l}\text { Hypertension, LV } \\
\text { dysfunction }\end{array}$ \\
\hline Trastuzumab & Antibody HER-2 (Biologic agents) & Breast, gastric, gastro-esophageal & LV dysfunction \\
\hline Ramucirumab & Antibody VEGFR-2 (Biologic agents) & Colon, rectal, gastric, lung & Hypertension, thromboembolism \\
\hline Interleukin-2 (IL-2) & Immune agent & Melanoma, renal & $\begin{array}{l}\text { Capillary leak syndrome, hypotension, } \\
\text { myocardial toxicity }\end{array}$ \\
\hline Interferon-Alpha (INF) & Immune agent & Melanoma, renal, lymphoma & Arrhythmias, ischemia \\
\hline
\end{tabular}

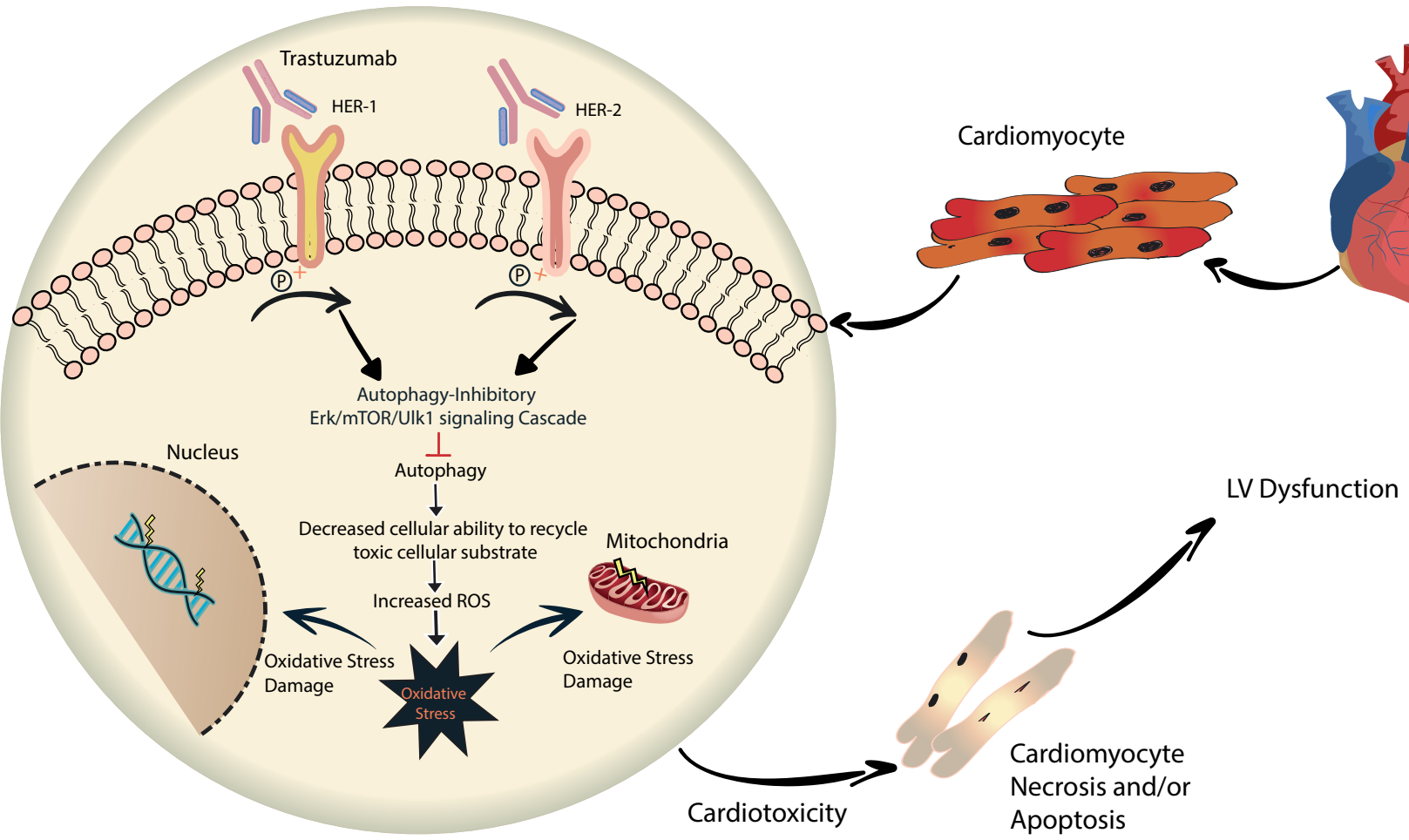

Figure 1. Trastuzumab is directed against the extracellular part of HER2 in HER-2 positive breast cancer patients. This agent causes the phosphorylation of tyrosine 845 (Y845) and 1248 (Y1248) at HER-1 and HER-2, respectively. This process activates the Erk/mTOR/ Ulk1 signalling cascade that inhibits autophagy in the primary cardiomyocytes. Subsequently, autophagy inhibition increases the intracellular level of reactive oxygen species (ROS) leading to oxidative stress in cardiomyocytes, resulting in apoptosis or necrosis of cardiomyocytes. Additionally, trastuzumab alters ultrastructural formation, and also expression profile of genes and DNA repair. These structural and genetic changes increase myocardial increased myocardial oxidative and nitrative stress and potentially activates apoptotic pathways in cardiomyocytes

\section{Nuclear cardiac imaging in cardio-oncology}

Cardio-oncology balances correct patient-centred treatment procedures and cardiovascular disorders. Therefore, it needs a multi-disciplinary team including cardiologists, oncologists, and nuclear medicine specialists for the best efficiency in understanding, treating, and preventing cardiovascular disease [10, 50].
Non-invasive cardiovascular imaging modalities with their versatility have caused a revolution in this field. There are many imaging techniques, but the most common practical procedures are two-dimensional echocardiography and multi-gated acquisition imaging, which evaluate resting left ventricle ejection fraction. Nuclear medicine using different radiotracers has a long history in the identification and management of myocardial cardiotoxicity (Tab. 2) [15]. 
Table 2. Important radiotracers in cardiac nuclear imaging for cardiotoxicity

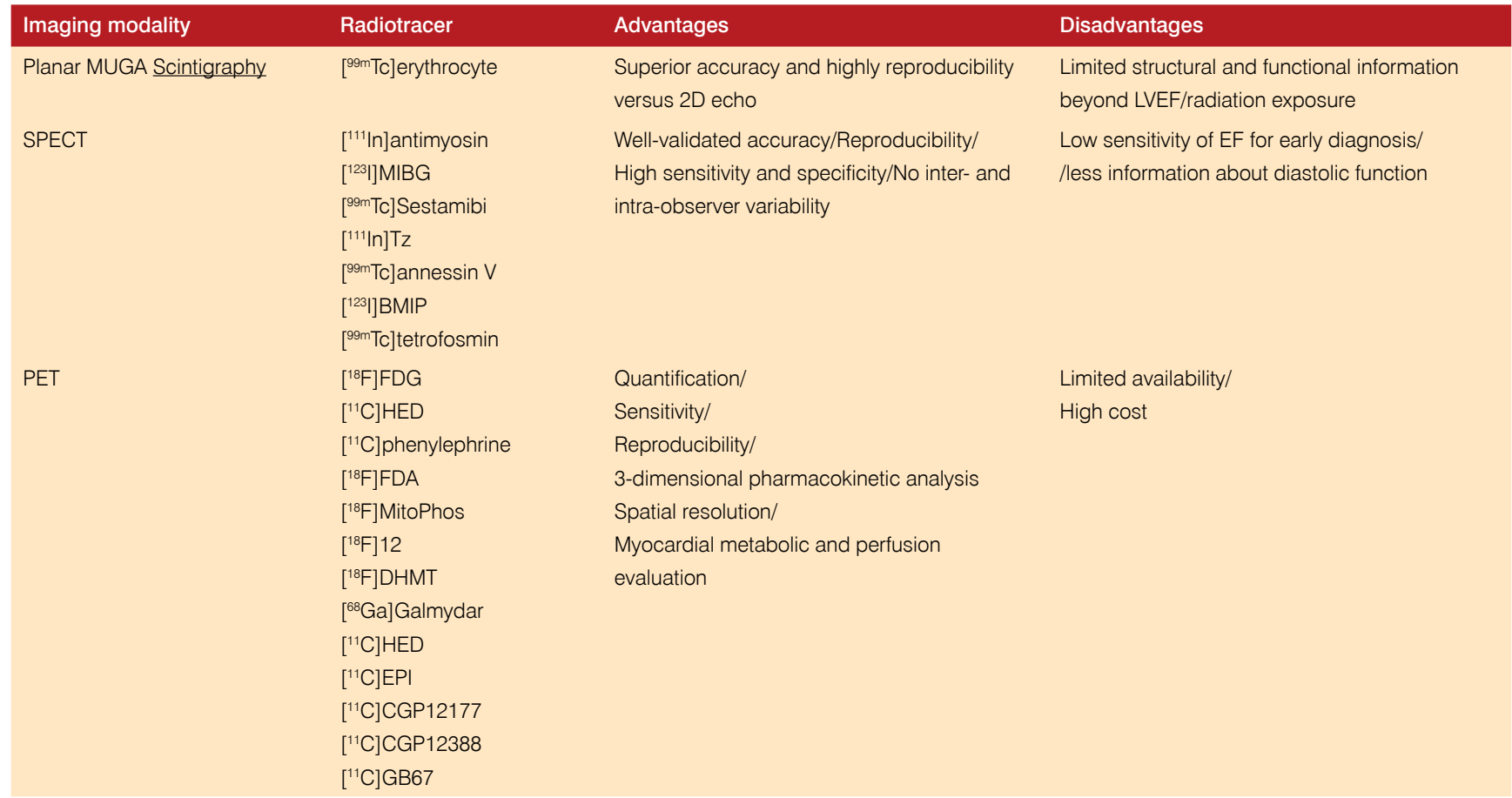

\section{[99mTc]Multi-Gated Acquisition Scan (MUGAs)}

A multi-gated acquisition scan is reproducible and provides the most accurate radionuclide ventriculography to visualize the cardiac blood pool. [ $\left.{ }^{99 m} \mathrm{Tc}\right]$ erythrocyte camera scintigraphy, also known as equilibrium radionuclide angiocardiography, assesses cardiac blood pool and its function for treatment response and collects prognostic information for patients with cardiac haemorrhage. One of the accepted cost-effective methods for cardiac monitoring of patients undergoing trastuzumab treatment is MUGAs. The results of the MUGA scan indicate cardiotoxicity if the LEVF decreases more than $10 \%$ (to a final ejection fraction of less than $50 \%$ ) [51].

A study by Schwartz et al found the superiority of MUGA for monitoring cardiotoxicity and identifying cognitive heart failure in cancer survivors [52]. Additionally, MUGA is considered a promising choice for detecting the asymptomatic reduction of LVEF.

A serial cross-sectional study compared the use of three conventional cardiac imaging methods for chemotherapy-related cardiotoxicity. The major disadvantages of MUGA were high radiation exposure and the inability to provide information about the right ventricular, valvular, or pericardial disease [13]. The use of the MUGA scan decreased between 2011 and 2014 and two imaging methods including echo and cardiovascular magnetic resonance imaging were used instead. These results may be due to increased knowledge of patients and physicians about radiation risks associated with serial radionuclide ventriculography scans. Moreover, the findings of serial radionuclide ventriculography are similar to the findings of echocardiography and cardiac magnetic resonance imaging [53].

\section{Single-photon emission computed tomography (SPECT)}

Three-dimensional gated blood pool SPECT is similar to the previous method, but it has the potential to differentiate cardiac chambers better than planar radionuclide ventriculography. Automatic measurement of the LVEF by [ ${ }^{99 m} \mathrm{Tc}$ ] gated blood-pool SPECT (GBPS) provides accurate segmental wall motion analysis and estimates the cavity volume in a single examination [54, 55]. Nevertheless, there is a good agreement in the rough calculation of LVEF between MUGA and GBPS methods [56].

Anthracycline drugs are used to treat many different malignancies such as lymphoma, leukaemia, myeloma, breast carcinoma, lung, ovarian, and gastric. They are also induced cardiotoxicity inducing cardiomyopathy, valvular heart disease, coronary heart disease, and heart failure $[57,58]$. Two important mechanisms correlated with anthracycline-cardiotoxicity are mitochondrial dys-

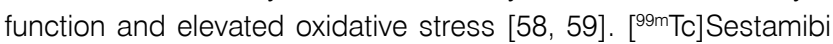
SPECT imaging is important in vivo molecular scan approach that enables interrogation of mitochondrial dysfunction and detection of doxorubicin-induced cardiotoxicity [60].

Moreover, myocardial abnormalities can be detected through ${ }^{123}$-labeled metaiodobenzylguanidine ([$\left.\left.{ }^{123} \mid\right] \mathrm{MIBG}\right)$ scan before causing permanent excessive left ventricular impairment. [ $\left.{ }^{123}\right]$ MIBG is a norepinephrine analog radiotracer. This radiotracer shows appropriate reproducibility and sensitivity for the evaluation of myocardial adrenergic disorders.

In a study using myocardial perfusion imaging with [ $\left.\left.{ }^{123}\right]\right] \mathrm{MIBG}$ and $\left[{ }^{123} \mid\right]$ BMIPP for patients undergoing anthracycline treatment agents, the results showed early detection of anthracycline-related 
cardiotoxicity through $\left[{ }^{123}\right]$ MIBG. Early diagnosis results in a lower incidence and intensity of heart damage in these patients [61-63].

Indium-111 labelled antimyosin antibody as the main marker of myocardial cell necrosis has been introduced for direct visualization of myocyte damage. The myocardial uptake of this radiotracer correlates with the LVEF decrease in patients treated with an anthracycline. Additionally, ${ }^{111}$ In-antimyosin SPECT imaging can identify cardiotoxicity associated with anthracycline chemotherapy regimens in breast cancer patients as well as the doxorubicin regimen in leukaemia, lymphoma, and other solid tumours [64-66].

Several preclinical results using the $\left[{ }^{99 \mathrm{~m} T c}\right.$ ]Annexin $\mathrm{V}$ scan confirmed the significant role of this radiotracer in the detection of myocardial apoptosis. [ ${ }^{99 \mathrm{~m} T c]}$ Annexin $\mathrm{V}$ scintigraphy successfully detected apoptotic cells in myocarditis, acute myocardial infarction, the curative effect of anti-apoptosis medications in heart ischemia patients, unstable atherosclerotic plaque, cardiac transplant rejection, and a cardiotoxicity-related anthracycline [67-72]. Additional clinical studies are needed to assess the common use of this radiotracer, especially for early detection of myocardial damage associated with anticancer drugs.

Long-chain fatty acids, as a vital nutrient for the myocardium, are metabolized by $\beta$-oxidation. These fatty acids or related analogues can be used in specific imaging probes ([23] $]$ labelled fatty acids) to assess oxidative differentiation in multiple cardiac diseases [73]. Nevertheless, this radiotracer has not been used in SPECT imaging due to its instability in vivo. Therefore, novel tracers such as ${ }^{1231-15-(p-i o d o p h e n y l)-3-m e t h y l ~ p e n t a d e c a n o i c ~}$ acid (BMIPP) have emerged, which have demonstrated promising results in nuclear cardiology $[74,75]$.

Some studies examined ${ }^{111}$ In-DTPA-trastuzumab imaging techniques to visualize the human epidermal growth factor receptor 2 (HER2) expressed by myocytes in breast cancer patients. Trastuzumab has been used as a monoclonal antibody to bind to HER2 for curative purposes. This radiotracer has been used to detect patients potentially subject to trastuzumab-related cardiotoxicity. This technique may be helpful, especially in patients with high-risk cardiac failure [76-80]. Regardless of the predictive role of this radiotracer, the data are limited, and this method has not yet been used in conventional clinical practice.

\section{Positron emission tomography (PET)}

More common imaging procedures, such as computed tomography (CT) scan, nuclear magnetic resonance (NMR), and magnetic resonance imaging (MRI), define anatomic and physiological functional properties; nonetheless, they cannot determine the autogenetic myocardial biochemistry. Positron emission tomography (PET) assesses both myocardial metabolism and perfusion with a better resolution and higher sensitivity $[81,82]$. Moreover, PET myocardial tracers provide an extensive and detailed evaluation of early and reversible cardiotoxic effects of anticancer treatment regimens. The uptake of fluorine-18-fluorodeoxyglucose ( $\left.\left[{ }^{18} \mathrm{~F}\right] \mathrm{FDG}\right)$ increases in cardiomyocytes before the LVEF decrease in patients treated with anthracyclines [83].

Reactive oxygen species (ROS) have been involved in cell signalling, homeostasis. However, a high number of ROS causes pathogenesis of a high number of human diseases and drug toxicities, so the development of imaging tools that able to characterize
ROS biology in vivo has been recently considered and turned into a big challenge [84]. The ${ }^{18} \mathrm{~F}-12$ microPET imaging of the heart in mice with Doxorubicin-induced cardiac inflammation indicated 2-fold higher oxidation of this tracer compared to the control group. These findings showed that compound 12 is a suitable PET tracer for in vivo imaging of ROS [85]. Another PET tracer that evaluated superoxide production for early detection of doxorubicin-induced cardiotoxicity is ${ }^{18} \mathrm{~F}-\mathrm{DHMT}$. This tracer detected excessive production of reactive oxygen species before a decrease in LVEF that may give a good chance for early cardiotoxicity detection in patients with malignancies [86]. Moreover, $\left[{ }^{68} \mathrm{Ga}\right]$ Galmydar is also evaluated as a potential radiotracer to monitor Doxorubicin-induced cardiomyopathy in different situations. MicroPET/CT scan showed a high-resolution non-invasive assessment of metabolic changes related to Doxorubicin treatment using ${ }^{68} \mathrm{Ga}$-Galmydar at the earliest stages. Single-cell imaging and quantitative biodistribution demonstrated that Galmydar localized precisely in mitochondria of treated cells with Doxorubicin [87]

${ }^{18} \mathrm{~F}$-MitoPhos as radiolabelled lipophilic cations was used for early detection of imaging cardiotoxicity in acute doxorubicin in the rat model. $\left[{ }^{18} \mathrm{~F}\right]$ MitoPhos PET imaging demonstrated appropriate pharmacokinetic parameters for cardiac imaging and was introduced as a promising radiopharmaceutical for imaging chemotherapy-induced cardiotoxicity [88].

It has been recently demonstrated that [ $\left.{ }^{2} \mathrm{Rb}\right] \mathrm{PET}$ imaging could be a potential radiotracer for quantitative assessment of the myocardial blood flow in patients that are at high risk for anthracycline cardiotoxicity $[15,89]$. Several studies are investigating nuclear cardiac imaging for the early detection of cardiotoxicity-related cancer therapy modalities. Important radiotracers used for investigating cardiotoxicity in cardiac nuclear imaging are summarized in Table 2.

\section{Can treatment nuclear medicine modalities stimulate cancer therapy- related cardiotoxicity?}

Another important modality for the treatment of malignancies is using injectable radiopharmaceuticals, which, similar to other treatment methods, require the assessment of possible side effects including cardiotoxicity.

One of the important approaches in nuclear medicine is theranostics, which combines diagnostic imaging and therapeutic methods through labelling the same molecule or the same agent with distinct radionuclides. More knowledge in genomics led to detecting theranostic biomaterials to diagnosis and treatment of malignancies along with molecular imaging tools. Cancer lesions are heterogeneous and therefore common treatment approaches may not provide favourable results. Nevertheless, these lesions can be detected through theranostics. Therefore, this characteristic can be used to determine which patient will benefit from therapy and which patient may not receive conventional treatments.

Theranostics is currently considered as the recommended modality not only for diagnosis and treatment of malignancies but also for staging, follow-up, monitoring response to treatment, and restaging. An important characteristic of this approach is delivering high doses to tumours while sparing non-targeted tissues.

Different theranostic probes have been developed from clinical experiments of radioactive iodine for evaluation of physiologic 
metabolism and thyroid disorders to recent applications in neuroendocrine tumours and prostate cancer. Some pairs of radionuclides that have been used in theranostics include diagnostic gamma or positron emission radionuclides such as ${ }^{123}\left(\mathrm{t}_{1 / 2}=13.22 \mathrm{~h}\right)$, ${ }^{124} \mathrm{l}\left(\mathrm{t}_{1 / 2}=4.2 \mathrm{~d}\right),{ }^{68} \mathrm{Ga}\left(\mathrm{t}_{1 / 2}=68 \mathrm{~min}\right),{ }^{99 \mathrm{mTc}}\left(\mathrm{t}_{1 / 2}=6 \mathrm{~h}\right),{ }^{111} \mathrm{In}\left(\mathrm{t}_{1 / 2}=2.81\right.$ d), and therapeutic high-dose radioactive materials such as ${ }^{177} \mathrm{Lu}$ $\left(\mathrm{t}_{1 / 2}=6.71 \mathrm{~d}\right)$ and ${ }^{90} \mathrm{Y}\left(\mathrm{t}_{1 / 2}=64.02 \mathrm{~h}\right)$. Therapeutic radionuclides emit beta and alpha particles, causing damage to double-stranded DNA and death in cancer cells. The most common available pairs of theranostic radiopharmaceuticals include $\left[{ }^{68} \mathrm{Ga}\right] \mathrm{PSMA} /\left[{ }^{177} \mathrm{Lu}\right] \mathrm{PSMA}$ for prostate cancer and $\left.{ }^{68} \mathrm{Ga}\right] D O T A T A T E /\left[{ }^{177} \mathrm{Lu}\right] \mathrm{DOTATATE}$ for neuroendocrine (NETs) (Fig. 2 and 3).

Theranostics is a form of systemic endo-radiotherapy that delivers toxic radiation to target cells but some side effects including severe hematotoxicity and nephrotoxicity have been reported. Many studies evaluated early and late side effects of radioligand therapy, especially peptide receptor radioligand therapy (PRRT), and found that side effects were almost entirely limited, predictable, and/or reversible [90-96]. Nonetheless, a recent case-report study found cardiotoxicity related PRRT in patients with metastatic neuroendocrine tumours.

Different radiotracers have been used in nuclear medicine to visualize and treat neuroendocrine tumours. These tumours develop in many tissues including the lungs, stomach, small intestine, appendix, colorectal tissue, and heart [97-99]. Somatostatin analogues are an inseparable component of diagnostic and treatment policies in metastatic carcinoid tumours. Neuroendocrine tumours have the potential to be targeted with radiopeptides due to peptide receptor expression. Peptide receptor radionuclide therapy using [ $\left[{ }^{90} Y\right]$ DOTATAC and [ $\left.{ }^{177} \mathrm{Lu}\right]$ DOTATATE have successful results in the treatment of inoperative and metastases liver cancers. PRRT can cause renal or haematological adverse effects, but the timely application of appropriate precautionary measures and safe dose administration decrease these toxicities $[100,101]$.
More than $50 \%$ of patients with advanced carcinoid tumours are prone to carcinoid heart disease [102]. At the time of carcinoid cardiac metastases, due to the expression of somatostatin receptors in the cardiac tissue (sst1, sst2, sst4, and sst5), caution should be practised to target neuroendocrine tumour cells with somatostatin-radioisotope compounds. [177Lu]DOTATATE is confirmed as an effective option in inoperative metastases of neuroendocrine tumours with symptomatic cardiovascular impairment [103].

In a case report study, a 51-year-old-man was diagnosed with neuroendocrine tumour lesions and received somatostatin analogue therapy. After a while, a ${ }^{68} \mathrm{Ga}$ ]DOTATATE scan was used to evaluate the patient. Imaging demonstrated that metastatic lesions spread in the axial skeleton, liver, and spleen as well as the right and even the left myocardium. The ejection fraction was normal (62\%) in the beginning. After receiving two cycles of [ $\left.{ }^{177} \mathrm{Lu}\right]$ labeled PRRT, an echocardiogram showed a serious decrease in the left ventricular systolic function and left ventricular ejection fraction (34\%). Therefore, PRRT stopped but it started again because the cardiac function continued to decline. In this case, the cardiac function was normal before treatment, but the patient developed cardiotoxicity after treatment due to the delivery of the radioactive isotope to metastatic lesions. This cardiotoxic effect should be considered as a precaution in a patient with neuroendocrine tumour and cardiac metastases receiving PRRT [104].

Moreover, recent advances in nuclear medicine imaging and therapy have shown that fibroblast activation protein (FAP) and chemokine receptor (CXCR) are promising targets for nuclear-labelled tumour probes. Different reports have indicated an effective role of $\left[{ }^{68} \mathrm{Ga}\right]$ pentixafor chemokine-directed imaging in some solid tumours such as glioblastoma, ovarian cancer, renal cell cancer, small cell lung cancer, and adrenocortical carcinoma. However, a study by Vag et al. questioned its possibility in other tumours including pancreatic cancer, sarcoma, and breast cancer [105-109].
A

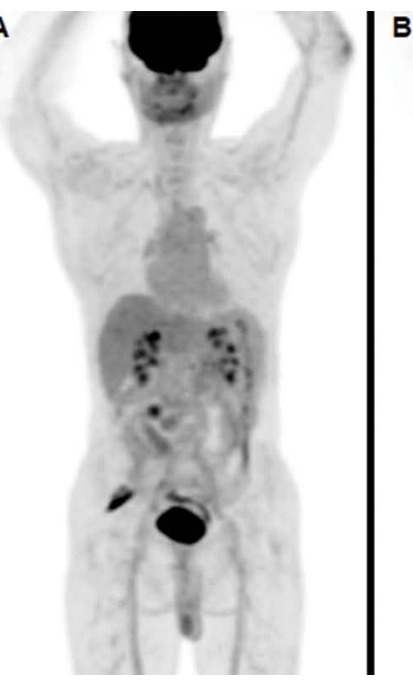

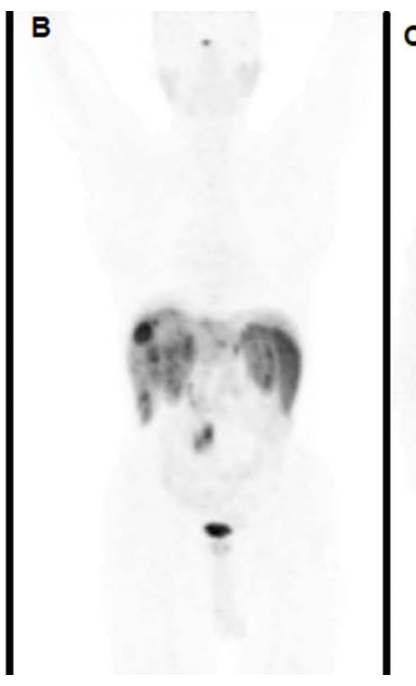
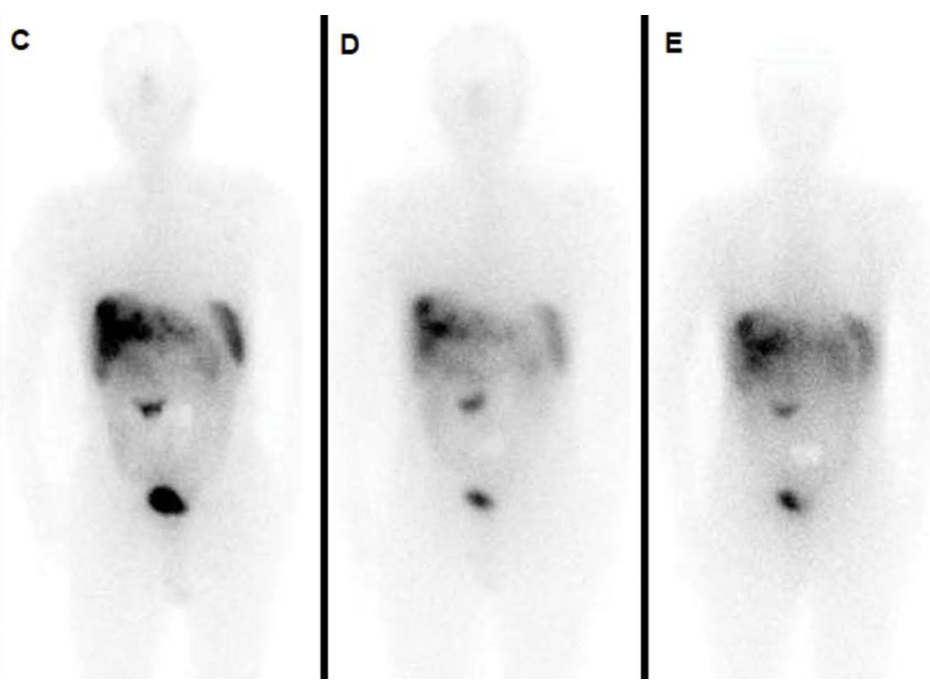

Figure 2. A 68-year-old man with metastatic neuroendocrine tumours refractory to chemotherapy presented for PRRT. Pre-treatment FDG PET (A) showed no abnormal radiotracer uptake, while all lesions in the liver and mid-abdomen revealed significant SSTR expression on pre-treatment 68Ga-DOTATATE PET/CT (B). The patients underwent 3 cycles of PRRT $(22.2 \mathrm{GBq})$. The post-treatment scintigraphy after the $1^{\text {st }} \mathrm{cycle}(\mathrm{C})$ indicated intensive uptake of radiotracer in the above regions, which decreased significantly in number and size in post-treatment scintigraphy after the $3^{\text {rd }}$ cycle $(D, E)$ 
A

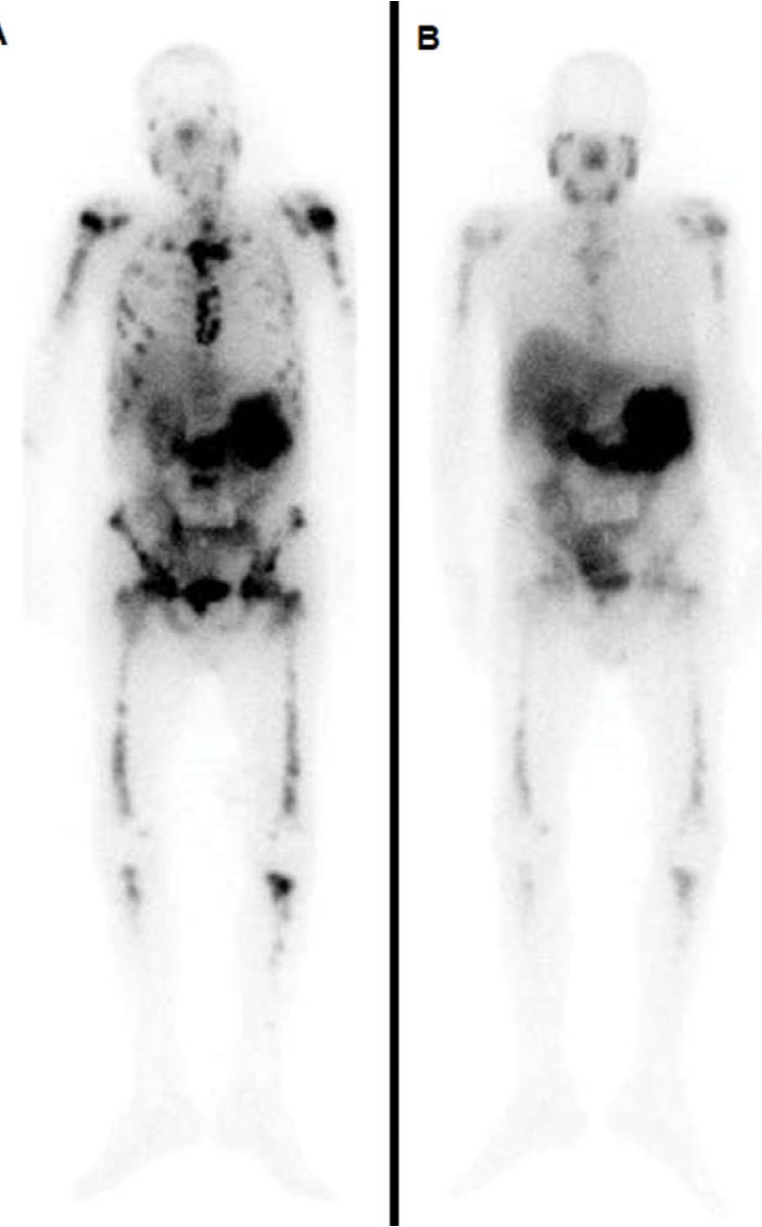

Figure 3. A 58-year-old man with metastatic castration-resistant prostate cancer refractory to different regimes of hormone therapy and chemotherapy presented for lutetium-177-labelled prostate-specific membrane antigen radioligand therapy. The patients underwent 3 cycles of [ $\left.{ }^{177} \mathrm{Lu}\right] \mathrm{PSMA}$ therapy $(22.2 \mathrm{GBq})$. Post-treatment scintigraphy after the $1^{\text {st }}$ cycle $(A)$ indicated widespread uptake of radiotracer throughout the entire body which decreased significantly in number and size in post-treatment scintigraphy after the $3^{\text {rd }}$ cycle (B)

${ }^{177}$ Lu-pentixather has demonstrated outstanding CXCR4-targeting properties and a favourable pharmacokinetic profile. Additionally, $\left[{ }^{68} \mathrm{Ga}\right.$ ]pentixafor/ ${ }^{177} \mathrm{Lu}$-pentixather based CXCR4-targeted theranostic approach delivers high doses to the tumour sparing healthy non-targeted cells [110]. Several malignant cells including head and neck, breast, lung, pancreatic, and oesophageal, colorectal cancer have a high uptake of $\left[{ }^{68} \mathrm{Ga}\right] \mathrm{FAPI}$ that can be used for non-invasive molecular imaging, locating the primary site of unknown malignancies, and staging of tumours. On the other hand, $\left.{ }^{68} \mathrm{Ga}\right]$ FAPI tracers contain universal DOTA chelators. This property makes it possible to label the ligand with a suitable therapeutic radionuclide for a theranostic approach [106, 111].

However, although no life-threatening side effects have been reported for these radioligands, concise studies should be performed to evaluated probable side effects and cardiotoxicity.

\section{Conclusion}

Cardio-oncology as a multi-modality approach has become a valuable strategy for improving treatment outcome and patient management through screening cardiotoxicity during cancer treatment. Several studies investigated cancer treatment cardiotoxicity in chemotherapy and external radiation therapy. In addition to the significant role of nuclear cardiac imaging procedures for early detection of cardiovascular changes, it is required to perform more comprehensive studies to investigate cancer treatment options such as PRRT, fibroblast activation protein, and chemokine receptor targeting probes for possible cardiac side effects that play important roles in the treatment of malignancies. Finally, it is required to establish a network of collaboration between oncologists, nuclear medicine specialists, and cardiologists to obtain optimal patient outcomes and decrease life-threatening cardiotoxicity.

\section{Ethics approval and consent to participate}

Not applicable.

\section{Availability of data and materials}

Not applicable.

\section{Conflict of interests}

The authors declare that they have no competing interests.

\section{Acknowledgements}

Not applicable.

\section{References}

1. Fuster V, Voûte J. MDGs: chronic diseases are not on the agenda. The Lancet. 2005; 366(9496): 1512-1514, doi: 10.1016/s0140-6736(05)67610-6.

2. Hofmann L, Forschner A, Loquai $C$, et al. Cutaneous, gastrointestinal, hepatic, endocrine, and renal side-effects of anti-PD-1 therapy. Eur $\mathrm{J}$ Cancer. 2016; 60: 190-209, doi: 10.1016/j.ejca.2016.02.025, indexed in Pubmed: 27085692.

3. Sivapackiam J, Sharma M, Schindler TH, et al. PET radiopharmaceuticals for imaging chemotherapy-induced cardiotoxicity. Curr Cardiol Rep. 2020; 22(8): 62, doi: 10.1007/s11886-020-01315-z, indexed in Pubmed: 32562004.

4. Herrmann J, Lerman A, Sandhu NP, et al. Evaluation and management of patients with heart disease and cancer: cardio-oncology. Mayo Clin Proc. 2014; 89(9): 1287-1306, doi: 10.1016/j.mayocp.2014.05.013, indexed in Pubmed: 25192616.

5. Lee CK, Aeppli D, Nierengarten ME. The need for long-term surveillance for patients treated with curative radiotherapy for Hodgkin's disease: University of Minnesota experience. Int J Radiat Oncol Biol Phys. 2000; 48(1): 169-179, doi: 10.1016/s0360-3016(00)00647-7, indexed in Pubmed: 10924987.

6. Jaworski C, Mariani JA, Wheeler G, et al. Cardiac complications of thoracic irradiation. J Am Coll Cardiol. 2013; 61(23): 2319-2328, doi: 10.1016/j. jacc.2013.01.090, indexed in Pubmed: 23583253.

7. Aapro M, Bernard-Marty C, Brain EGC, et al. Anthracycline cardiotoxicity in the elderly cancer patient: a SIOG expert position paper. Ann Oncol. 
2011; 22(2): 257-267, doi: 10.1093/annonc/mdq609, indexed in Pubmed: 20956616

8. Serrano C, Cortés J, De Mattos-Arruda L, et al. Trastuzumab-related cardiotoxicity in the elderly: a role for cardiovascular risk factors. Ann Oncol. 2012; 23(4): 897-902, doi: 10.1093/annonc/mdr348, indexed in Pubmed: 21828361

9. Jain D, Russell RR, Schwartz RG, et al. Cardiac complications of cancer therapy: pathophysiology, identification, prevention, treatment, and future directions. Curr Cardiol Rep. 2017; 19(5): 36, doi: 10.1007/s11886-0170846-x, indexed in Pubmed: 28374177.

10. Russell RR, Alexander J, Jain D, et al. The role and clinical effectiveness of multimodality imaging in the management of cardiac complications of cancer and cancer therapy. J Nucl Cardiol. 2016; 23(4): 856-884, doi: 10.1007/s12350-016-0538-8, indexed in Pubmed: 27251147.

11. Sardaro A, Petruzzelli MF, D'Errico MP, et al. Radiation-induced cardiac damage in early left breast cancer patients: risk factors, biological mechanisms, radiobiology, and dosimetric constraints. Radiother Oncol. 2012; 103(2): 133-142, doi: 10.1016/j.radonc.2012.02.008, indexed in Pubmed: 22391054

12. Hurtado-de-Mendoza D, Loaiza-Bonilla A, Bonilla-Reyes PA, et al. Cardio-oncology: cancer therapy-related cardiovascular complications in a molecular targeted era: new concepts and perspectives. Cureus. 2017; 9(5): e1258, doi: 10.7759/cureus.1258, indexed in Pubmed: 28649481

13. Plana JC, Galderisi M, Barac A, et al. Expert consensus for multimodality imaging evaluation of adult patients during and after cancer therapy: a report from the American Society of Echocardiography and the European Association of Cardiovascular Imaging. J Am Soc Echocardiogr. 2014; 27(9): 911-939, doi: 10.1016/i.echo.2014.07.012, indexed in Pubmed: 25172399.

14. Abdel-Qadir H, Austin PC, Lee DS, et al. A population-based study of cardiovascular mortality following early-stage breast cancer. JAMA Cardiol. 2017; 2(1): 88-93, doi: 10.1001/jamacardio.2016.3841, indexed in Pubmed: 27732702

15. Makavos G, Ikonomidis I, Palios J, et al. Cardiac imaging in cardiotoxicity: a focus on clinical practice. Heart Fail Rev. 2020 [Epub ahead of print], doi: 10.1007/s10741-020-09952-w, indexed in Pubmed: 32306221

16. Pondé NF, Lambertini M, de Azambuja E. Twenty years of anti-HER2 therapy-associated cardiotoxicity. ESMO Open. 2016; 1(4): e000073, doi: 10.1136/esmoopen-2016-000073, indexed in Pubmed: 27843627.

17. Bovelli D, Plataniotis G, Roila F, et al. ESMO Guidelines Working Group. Cardiotoxicity of chemotherapeutic agents and radiotherapy-related heart disease: ESMO Clinical Practice Guidelines. Ann Oncol. 2010; 21(Suppl 5): v277-v282, doi: 10.1093/annonc/mdq200, indexed in Pubmed: 20555097.

18. Donnellan E, Phelan D, McCarthy CP, et al. Radiation-induced heart disease: A practical guide to diagnosis and management. Cleve Clin J Med. 2016; 83(12): 914-922, doi: 10.3949/ccjm.83a.15104, indexed in Pubmed: 27938516.

19. Aleman BMP, van den Belt-Dusebout AW, Klokman WJ, et al. Long-term cause-specific mortality of patients treated for Hodgkin's disease. J Clin Oncol. 2003; 21(18): 3431-3439, doi: 10.1200/JC0.2003.07.131, indexed in Pubmed: 12885835

20. Cutter DJ, Darby SC, Yusuf SW. Risks of heart disease after radiotherapy. Tex Heart Inst J. 2011; 38(3): 257-258, indexed in Pubmed: 21720464

21. Early Breast Cancer Trialists' Collaborative Group (EBCTCG). Effects of radiotherapy and of differences in the extent of surgery for early breast cancer on local recurrence and 15-year survival: an overview of the randomised trials. The Lancet. 2005; 366(9503): 2087-2106, doi: 10.1016/s01406736(05)67887-7.

22. Popescu CC, Olivotto IA, Beckham WA, et al. Volumetric modulated arC therapy improves dosimetry and reduces treatment time compared to conventional intensity-modulated radiotherapy for locoregional radiotherapy of left-sided breast cancer and internal mammary nodes. Int J Radiat Oncol Biol Phys. 2010; 76(1): 287-295, doi: 10.1016/j.jirobp.2009.05.038, indexed in Pubmed: 19775832
23. Osman SOS, Hol S, Poortmans PM, et al. Volumetric modulated arc therapy and breath-hold in image-guided locoregional left-sided breast irradiation. Radiother Oncol. 2014; 112(1): 17-22, doi: 10.1016/j.radonc.2014.04.004, indexed in Pubmed: 24825176.

24. Sakumi A, Shiraishi K, Onoe T, et al. Single-arc volumetric modulated arc therapy planning for left breast cancer and regional nodes. J Radiat Res. 2012; 53(1): 151-153, doi: 10.1269/jrr.11159, indexed in Pubmed: 22240941.

25. Lauche O, Kirova YM. Helical tomotherapy in breast cancer treatment. Breast Cancer Management. 2014; 3(5): 441-449, doi: 10.2217/bmt.14.34.

26. Lohr F, El-Haddad M, Dobler B, et al. Potential effect of robust and simple IMRT approach for left-sided breast cancer on cardiac mortality. Int J Radiat Oncol Biol Phys. 2009; 74(1): 73-80, doi: 10.1016/j.jjrobp.2008.07.018, indexed in Pubmed: 18973977.

27. Tan W, Wang X, Qiu D, et al. Dosimetric comparison of intensity-modulated radiotherapy plans, with or without anterior myocardial territory and left ventricle as organs at risk, in early-stage left-sided breast cancer patients. Int J Radiat Oncol Biol Phys. 2011; 81(5): 1544-1551, doi: 10.1016/j. ijrobp.2010.09.028, indexed in Pubmed: 21470785.

28. Cao J, Roeske JC, Chmura SJ, et al. Calculation and prediction of the effect of respiratory motion on whole breast radiation therapy dose distributions. Med Dosim. 2009; 34(2): 126-132, doi: 10.1016/j.meddos.2008.07.002, indexed in Pubmed: 19410141

29. Borst GR, Sonke JJ, den Hollander S, et al. Clinical results of image-guided deep inspiration breath hold breast irradiation. Int J Radiat Oncol Biol Phys. 2010; 78(5): 1345-1351, doi: 10.1016/j.jijrobp.2009.10.006, indexed in Pubmed: 20207496.

30. Lymberis SC, deWyngaert JK, Parhar $\mathrm{P}$, et al. Prospective assessment of optimal individual position (prone versus supine) for breast radiotherapy: volumetric and dosimetric correlations in 100 patients. Int J Radiat Oncol Biol Phys. 2012; 84(4): 902-909, doi: 10.1016/j.jjrobp.2012.01.040, indexed in Pubmed: 22494590.

31. Bradley JA, Dagan R, Ho MW, et al. Initial report of a prospective dosimetric and clinical feasibility trial demonstrates the potential of protons to increase the therapeutic ratio in breast cancer compared with photons. Int J Radiat Oncol Biol Phys. 2016; 95(1): 411-421, doi: 10.1016/j.jijobp.2015.09.018, indexed in Pubmed: 26611875

32. Coon AB, Dickler A, Kirk MC, et al. Tomotherapy and multifield intensity-modulated radiotherapy planning reduce cardiac doses in left-sided breast cancer patients with unfavorable cardiac anatomy. Int J Radiat Oncol Biol Phys. 2010; 78(1): 104-110, doi: 10.1016/j.jjobp.2009.07.1705, indexed in Pubmed: 20004529.

33. Kirova YM, Gambotti L, De Rycke Y, et al. Risk of second malignancies after adjuvant radiotherapy for breast cancer: a large-scale, single-institution review. Int J Radiat Oncol Biol Phys. 2007; 68(2): 359-363, doi: 10.1016/j. ijrobp.2006.12.011, indexed in Pubmed: 17379448.

34. Lally BE, Detterbeck FC, Geiger AM, et al. The risk of death from heart disease in patients with nonsmall cell lung cancer who receive postoperative radiotherapy: analysis of the surveillance, epidemiology, and end results database. Cancer. 2007; 110(4): 911-917, doi: 10.1002/cncr.22845, indexed in Pubmed: 17620279

35. Wang K, Pearlstein KA, Patchett ND, et al. Heart dosimetric analysis of three types of cardiac toxicity in patients treated on dose-escalation trials for Stage III non-small-cell lung cancer. Radiother Oncol. 2017; 125(2): 293-300, doi: 10.1016/j.radonc.2017.10.001, indexed in Pubmed: 29050957.

36. Kimmick GG, Lenihan DJ, Sawyer DB, Mayer EL, Hershman DL. Cardio-oncology: the clinical overlap of cancer and heart disease. Springer, Cham 2017

37. Luminari S, Montanini A, Caballero D, et al. Nonpegylated liposomal doxorubicin (MyocetTM) combination (R-COMP) chemotherapy in elderly patients with diffuse large B-cell lymphoma (DLBCL): results from the phase II EUR018 trial. Ann Oncol. 2010; 21(7): 1492-1499, doi: 10.1093/annonc/mdp544, indexed in Pubmed: 20007997 
38. Cardinale D, Sandri MT, Martinoni A, et al. Left ventricular dysfunction predicted by early troponin I release after high-dose chemotherapy. J Am Coll Cardiol. 2000; 36(2): 517-522, doi: 10.1016/s0735-1097(00)00748-8, indexed in Pubmed: 10933366.

39. Drews J. Drug discovery: a historical perspective. Science. 2000; 287(5460): 1960-1964, doi: 10.1126/science.287.5460.1960, indexed in Pubmed: 10720314.

40. Ferrara N. Vascular endothelial growth factor: basic science and clinical progress. Endocr Rev. 2004; 25(4): 581-611, doi: 10.1210/er.2003-0027, indexed in Pubmed: 15294883.

41. Ferrara N. VEGF and the quest for tumour angiogenesis factors. Nat Rev Cancer. 2002; 2(10): 795-803, doi: 10.1038/nrc909, indexed in Pubmed: 12360282

42. Shabalala S, Muller CJF, Louw J, et al. Polyphenols, autophagy and doxorubicin-induced cardiotoxicity. Life Sci. 2017; 180: 160-170, doi: 10.1016/j. Ifs.2017.05.003, indexed in Pubmed: 28478263.

43. Novo G, Cadeddu C, Sucato V, et al. Role of biomarkers in monitoring antiblastic cardiotoxicity. J Cardiovasc Med (Hagerstown). 2016; 17(Suppl 1): S27-S34, doi: 10.2459/JCM.0000000000000379, indexed in Pubmed: 27183522

44. Hall PS, Harshman LC, Srinivas S, et al. The frequency and severity of cardiovascular toxicity from targeted therapy in advanced renal cell carcinoma patients. JACC Heart Fail. 2013; 1(1): 72-78, doi: 10.1016/j.jchf.2012.09.001, indexed in Pubmed: 24621801.

45. Qi WX, Fu S, Zhang Q, et al. Bevacizumab increases the risk of severe congestive heart failure in cancer patients: an up-to-date meta-analysis with a focus on different subgroups. Clin Drug Investig. 2014; 34(10): 681-690, doi: 10.1007/s40261-014-0222-1, indexed in Pubmed: 25096848.

46. Groarke JD, Choueiri TK, Slosky D, et al. Recognizing and managing left ventricular dysfunction associated with therapeutic inhibition of the vascular endothelial growth factor signaling pathway. Curr Treat Options Cardiovasc Med. 2014; 16(9): 335, doi: 10.1007/s11936-014-0335-0, indexed in Pubmed: 25099086.

47. Choueiri TK, Mayer EL, Je Y, et al. Congestive heart failure risk in patients with breast cancer treated with bevacizumab. J Clin Oncol. 2011; 29(6): 632-638, doi: 10.1200/JCO.2010.31.9129, indexed in Pubmed: 21205755.

48. Moja L, Tagliabue L, Balduzzi S, et al. Trastuzumab containing regimens for early breast cancer. Cochrane Database Syst Rev. 2012(4): CD006243, doi: 10.1002/14651858.CD006243.pub2, indexed in Pubmed: 22513938.

49. Blackwell KL, Pegram MD, Tan-Chiu E, et al. Single-agent lapatinib for HER2-overexpressing advanced or metastatic breast cancer that progressed on first- or second-line trastuzumab-containing regimens. Ann Oncol. 2009; 20(6): 1026-1031, doi: 10.1093/annonc/mdn759, indexed in Pubmed: 19179558.

50. Patnaik JL, Byers T, DiGuiseppi C, et al. Cardiovascular disease competes with breast cancer as the leading cause of death for older females diagnosed with breast cancer: a retrospective cohort study. Breast Cancer Res. 2011; 13(3): R64, doi: 10.1186/bcr2901, indexed in Pubmed: 21689398.

51. Bellenger NG, Burgess MI, Ray SG, et al. Comparison of left ventricular ejection fraction and volumes in heart failure by echocardiography, radionuclide ventriculography and cardiovascular magnetic resonance; are they interchangeable? Eur Heart J. 2000; 21(16): 1387-1396, doi: 10.1053/euhj.2000.2011, indexed in Pubmed: 10952828.

52. Schwartz RG, Jain D, Storozynsky E. Traditional and novel methods to assess and prevent chemotherapy-related cardiac dysfunction noninvasively. J Nucl Cardiol. 2013; 20(3): 443-464, doi: 10.1007/s12350-013-9707-1, indexed in Pubmed: 23572315

53. Kolla BC, Roy SS, Duval S, et al. Cardiac imaging methods for chemotherapy-related cardiotoxicity screening and related radiation exposure: current practice and trends. Anticancer Res. 2017; 37(5): 2445-2449, doi: 10.21873/anticanres.11584, indexed in Pubmed: 28476812

54. Wexler O, Yoder SR, Elder JL, et al. Effect of gender on cardiovascular risk stratification with ECG gated SPECT left ventricular volume indices and ejection fraction. J Nucl Cardiol. 2009; 16(1): 28-37, doi: 10.1007/s12350008-9000-x, indexed in Pubmed: 19152126.

55. Liu YH, Fazzone-Chettiar R, Sandoval V, et al. New approach for quantification of left ventricular function from low-dose gated bloodpool SPECT: Validation and comparison with conventional methods in patients. J Nucl Cardiol. 2019 [Epub ahead of print], doi: 10.1007/s12350-019-01823-8, indexed in Pubmed: 31338796.

56. Groch MW, DePuey EG, Belzberg AC, et al. Planar imaging versus gated blood-pool SPECT for the assessment of ventricular performance: a multicenter study. J Nucl Med. 2001; 42(12): 1773-1779, indexed in Pubmed: 11752072.

57. Lipshultz SE, Karnik R, Sambatakos P, et al. Anthracycline-related cardiotoxicity in childhood cancer survivors. Curr Opin Cardiol. 2014; 29(1): 103-112, doi: 10.1097/HCO.0000000000000034, indexed in Pubmed: 24284979.

58. Cutter DJ, Schaapveld M, Darby SC, et al. Risk of valvular heart disease after treatment for Hodgkin lymphoma. J Natl Cancer Inst. 2015; 107(4): djv008, doi: 10.1093/jnci/djv008, indexed in Pubmed: 25713164.

59. Ichikawa $Y$, Ghanefar M, Bayeva M, et al. Cardiotoxicity of doxorubicin is mediated through mitochondrial iron accumulation. J Clin Invest. 2014; 124(2): 617-630, doi: 10.1172/JCl72931, indexed in Pubmed: 24382354.

60. Safee ZM, Baark F, Waters ECT, et al. Detection of anthracycline-induced cardiotoxicity using perfusion-corrected Tc sestamibi SPECT. Sci Rep. 2019; 9(1): 216, doi: 10.1038/s41598-018-36721-5, indexed in Pubmed: 30659226.

61. Carrió I, Estorch M, Berná L, et al. Indium-111-antimyosin and iodine-123MIBG studies in early assessment of doxorubicin cardiotoxicity. J Nucl Med. 1995; 36(11): 2044-2049, indexed in Pubmed: 7472595.

62. Russell RR, Zaret BL. Nuclear cardiology: present and future. Curr Probl Cardiol. 2006; 31(9): 557-629, doi: 10.1016/j.cpcardiol.2006.05.002, indexed in Pubmed: 16935694

63. Rosa GM, Gigli L, Tagliasacchi MI, et al. Update on cardiotoxicity of anti-cancer treatments. Eur J Clin Invest. 2016; 46(3): 264-284, doi: 10.1111/eci.12589, indexed in Pubmed: 26728634

64. Wenningmann N, Knapp M, Ande A, et al. Insights into Doxorubicin-induced Cardiotoxicity: Molecular Mechanisms, Preventive Strategies, and Early Monitoring. Mol Pharmacol. 2019; 96(2): 219-232, doi: 10.1124/mol.119.115725, indexed in Pubmed: 31164387

65. Jones RL, Swanton C, Ewer MS. Anthracycline cardiotoxicity. Expert Opin Drug Saf. 2006; 5(6): 791-809, doi: 10.1517/14740338.5.6.791, indexed in Pubmed: 17044806

66. Pepe A, Pizzino F, Gargiulo P, et al. Cardiovascular imaging in the diagnosis and monitoring of cardiotoxicity: cardiovascular magnetic resonance and nuclear cardiology. J Cardiovasc Med (Hagerstown). 2016; 17(Suppl 1): S45-S54, doi: 10.2459/JCM.0000000000000380, indexed in Pubmed: 27183525.

67. Blankenberg FG. In vivo detection of apoptosis. J Nucl Med. 2008; 49(Suppl 2): 81S-95S, doi: 10.2967/jnumed.107.045898, indexed in Pubmed: 18523067

68. Wang $X$, Liu $Y$, Wang $X$, et al. The role of $(99 m)$ Tc-annexin $V$ apoptosis scintigraphy in visualizing early stage glucocorticoid-induced femoral head osteonecrosis in the rabbit. Biomed Res Int. 2016: 7067259, doi: 10.1155/2016/7067259, indexed in Pubmed: 26989689.

69. Boersma HH, Kietselaer BL, Stolk LML, et al. Past, present, and future of annexin A5: from protein discovery to clinical applications. J Nucl Med. 2005; 46(12): 2035-2050, indexed in Pubmed: 16330568

70. Kietselaer $\mathrm{BL}$, Reutelingsperger CPM, Boersma HH, et al. Noninvasive detection of programmed cell loss with $99 \mathrm{mTc}$-labeled annexin A5 in heart failure. J Nucl Med. 2007; 48(4): 562-567, doi: 10.2967/jnumed.106.039453, indexed in Pubmed: 17401092.

71. Taki J, Higuchi T, Kawashima A, et al. Effect of postconditioning on myocardial 99mTc-annexin-V uptake: comparison with ischemic preconditioning and caspase inhibitor treatment. J Nucl Med. 2007; 48(8): 1301-1307, doi: 10.2967/jnumed.106.037408, indexed in Pubmed: 17631551. 
72. Bennink RJ, van den Hoff MJ, van Hemert FJ, et al. Annexin $\mathrm{V}$ imaging of acute doxorubicin cardiotoxicity (apoptosis) in rats. J Nucl Med. 2004; 45(5): 842-848, indexed in Pubmed: 15136635.

73. Knapp FF, Kropp J. lodine-123-labelled fatty acids for myocardial single-photon emission tomography: current status and future perspectives. Eur J Nucl Med. 1995; 22(4): 361-381, doi: 10.1007/BF00941855, indexed in Pubmed: 7607269.

74. Elmaleh DR, Fischman AJ, Shoup TM. Method for monitoring blood flow and metabolic uptake in tissue with radiolabeled alkanoic acid. Google Patents. 2009: US8268291B2.

75. Hashimura H, Kiso K, Yamada N, et al. Myocardial impairment detected by late gadolinium enhancement in hypertrophic cardiomyopathy: comparison with 99mTc-MIBI/tetrofosmin and 123I-BMIPP SPECT. Kobe J Med Sci. 2013; 59(3): E81-E92, indexed in Pubmed: 24045217.

76. Nowsheen S, Viscuse PV, O'Sullivan CC, et al. Incidence, diagnosis, and treatment of cardiac toxicity from trastuzumab in patients with breast cancer. Curr Breast Cancer Rep. 2017; 9(3): 173-182, doi: 10.1007/s12609-0170249-4, indexed in Pubmed: 29225726.

77. Martín M, Esteva FJ, Alba E, et al. Minimizing cardiotoxicity while optimizing treatment efficacy with trastuzumab: review and expert recommendations. Oncologist. 2009; 14(1): 1-11, doi: 10.1634/theoncologist.2008-0137, indexed in Pubmed: 19147689.

78. McLarty K, Cornelissen B, Scollard DA, et al. Associations between the uptake of 111 In-DTPA-trastuzumab, HER2 density and response to trastuzumab (Herceptin) in athymic mice bearing subcutaneous human tumour xenografts. Eur J Nucl Med Mol Imaging. 2009; 36(1): 81-93, doi: 10.1007/s00259-008-0923-x, indexed in Pubmed: 18712381.

79. Perik PJ, Lub-De Hooge MN, Gietema JA, et al. Indium-111-labeled trastuzumab scintigraphy in patients with human epidermal growth factor receptor 2-positive metastatic breast cancer. J Clin Oncol. 2006; 24(15): 2276-2282, doi: 10.1200/JCO.2005.03.8448, indexed in Pubmed: 16710024.

80. de Korte MA, de Vries EGE, Lub-de Hooge MN, et al. 111Indium-trastuzumab visualises myocardial human epidermal growth factor receptor 2 expression shortly after anthracycline treatment but not during heart failure: a clue to uncover the mechanisms of trastuzumab-related cardiotoxicity. Eur J Cancer. 2007; 43(14): 2046-2051, doi: 10.1016/j.ejca.2007.06.024, indexed in Pubmed: 17719768

81. Bergmann SR, Fox KA, Geltman EM, et al. Positron emission tomography of the heart. Prog Cardiovasc Dis. 1985; 28(3): 165-194, doi: 10.1016/00330620(85)90014-3, indexed in Pubmed: 3877316

82. Yoshinaga K, Klein R, Tamaki N. Generator-produced rubidium-82 positron emission tomography myocardial perfusion imaging-From basic aspects to clinical applications. J Cardiol. 2010; 55(2): 163-173, doi: 10.1016/j. jjcc.2010.01.001, indexed in Pubmed: 20206068

83. Sarocchi M, Bauckneht M, Arboscello E, et al. An increase in myocardial 18-fluorodeoxyglucose uptake is associated with left ventricular ejection fraction decline in Hodgkin lymphoma patients treated with anthracycline. J Transl Med. 2018; 16(1): 295, doi: 10.1186/s12967-018-1670-9, indexed in Pubmed: 30359253.

84. Zhang W, Cai Z, Li L, et al. Optimized and automated radiosynthesis of [F] DHMT for translational imaging of reactive oxygen species with positron emission tomography. Molecules. 2016; 21(12): 1696, doi: 10.3390/molecules21121696, indexed in Pubmed: 27941676.

85. Chu W, Chepetan A, Zhou D, et al. Development of a PET radiotracer for non-invasive imaging of the reactive oxygen species, superoxide, in vivo. Org Biomol Chem. 2014; 12(25): 4421-4431, doi: 10.1039/c3ob42379d, indexed in Pubmed: 24847866

86. Boutagy NE, Wu J, Cai Z, et al. In vivo reactive oxygen species detection with a novel positron emission tomography tracer, F-DHMT, allows for early detection of anthracycline-induced cardiotoxicity in rodents. JACC Basic TransI Sci. 2018; 3(3): 378-390, doi: 10.1016/j.jacbts.2018.02.003, indexed in Pubmed: 30062224.
87. Sivapackiam J, Kabra S, Speidel S, et al. 68Ga-Galmydar: A PET imaging tracer for noninvasive detection of Doxorubicin-induced cardiotoxicity. PLoS One. 2019; 14(5): e0215579, doi: 10.1371/journal.pone.0215579, indexed in Pubmed: 31120912.

88. McCluskey SP, Haslop A, Coello C, et al. Imaging of chemotherapy-induced acute cardiotoxicity with f-labeled lipophilic cations. J Nucl Med. 2019; 60(12): 1750-1756, doi: 10.2967/jnumed.119.226787, indexed in Pubmed: 31147403.

89. Laursen $\mathrm{AH}$, Elming MB, Ripa RS, et al. Rubidium-82 positron emission tomography for detection of acute doxorubicin-induced cardiac effects in lymphoma patients. J Nucl Cardiol. 2020; 27(5): 1698-1707, doi: 10.1007/s12350-018-1458-6, indexed in Pubmed: 30298372.

90. Ahmadzadehfar H, Eppard E, Kürpig S, et al. Therapeutic response and side effects of repeated radioligand therapy with 177Lu-PSMA-DKFZ-617 of castrate-resistant metastatic prostate cancer. Oncotarget. 2016; 7(11): 12477-12488, doi: 10.18632/oncotarget.7245, indexed in Pubmed: 26871285.

91. Yordanova A, Mayer K, Brossart P, et al. Safety of multiple repeated cycles of Lu-octreotate in patients with recurrent neuroendocrine tumour. Eur J Nucl Med Mol Imaging. 2017; 44(7): 1207-1214, doi: 10.1007/s00259-0173652-1, indexed in Pubmed: 28246882.

92. Bodei L, Kidd M, Paganelli G, et al. Long-term tolerability of PRRT in 807 patients with neuroendocrine tumours: the value and limitations of clinical factors. Eur J Nucl Med Mol Imaging. 2015; 42(1): 5-19, doi: 10.1007/s00259-014-2893-5, indexed in Pubmed: 25273832.

93. Sabet A, Haslerud T, Pape UF, et al. Outcome and toxicity of salvage therapy with 177Lu-octreotate in patients with metastatic gastroenteropancreatic neuroendocrine tumours. Eur J Nucl Med Mol Imaging. 2014; 41(2): 205-210, doi: 10.1007/s00259-013-2547-z, indexed in Pubmed: 24030668.

94. Sabet A, Ezziddin K, Pape UF, et al. Long-term hematotoxicity after peptide receptor radionuclide therapy with 177Lu-octreotate. J Nucl Med. 2013; 54(11): 1857-1861, doi: 10.2967/jnumed.112.119347, indexed in Pubmed: 24009272.

95. Sabet A, Ezziddin K, Pape UF, et al. Accurate assessment of long-term nephrotoxicity after peptide receptor radionuclide therapy with (177) Lu-octreotate. Eur J Nucl Med Mol Imaging. 2014; 41(3): 505-510, doi: 10.1007/s00259-013-2601-x, indexed in Pubmed: 24196919.

96. Ahmadzadehfar H, Rahbar K, Kürpig S, et al. Early side effects and first results of radioligand therapy with (177)Lu-DKFZ-617 PSMA of castrate-resistant metastatic prostate cancer: a two-centre study. EJNMMI Res. 2015; 5(1): 114, doi: 10.1186/s13550-015-0114-2, indexed in Pubmed: 2609922.

97. Skrabanek P, Cannon D, Kirrane J, et al. Substance P secretion by carcinoid tumours. Ir J Med Sci. 1978; 147(2): 47-49, doi: 10.1007/BF02939369, indexed in Pubmed: 632061.

98. van der Lely AJ, de Herder WW. Carcinoid syndrome: diagnosis and medical management. Arq Bras Endocrinol Metabol. 2005; 49(5): 850-860, doi: 10.1590/s0004-27302005000500028, indexed in Pubmed: 16444370.

99. Werner RA, Bundschuh RA, Bundschuh L, et al. Molecular imaging reporting and data systems (MI-RADS): a generalizable framework for targeted radiotracers with theranostic implications. Ann Nucl Med. 2018; 32(8): 512-522, doi: 10.1007/s12149-018-1291-7, indexed in Pubmed: 30109562

100. Brabander T, van der Zwan WA, Teunissen JJM, et al. Long-term efficacy, survival, and safety of [177Lu, DOTA0, Tyr3] octreotate in patients with gastroenteropancreatic and bronchial neuroendocrine tumors. Clin Cancer Res. 2017; 23(16): 4617-4624, doi: 10.1158/1078-0432.CCR-16-2743, indexed in Pubmed: 28428192

101. Bergsma H, van Lom K, Raaijmakers MH, et al. Persistent hematologic dysfunction after peptide receptor radionuclide therapy with 177Lu-DOTATATE: incidence, course, and predicting factors in patients with gastroenteropancreatic neuroendocrine tumors. J Nucl Med. 2018; 59(3): 452-458, doi: 10.2967/jnumed.117.189712, indexed in Pubmed: 28775205. 
102. Hall R. Neoplastic heart disease. The heart, arteries and veins. McGraw-Hill, New York 1990: 1382-1403

103. Smith WHT, Nair RU, Adamson D, et al. Somatostatin receptor subtype expression in the human heart: differential expression by myocytes and fibroblasts. J Endocrinol. 2005; 187(3): 379-386, doi: 10.1677/joe.1.06082, indexed in Pubmed: 16423817.

104. Hendifar AE, Delpassand ES, Kittleson MM, et al. Cardiac toxicity in a patient receiving peptide receptor radionuclide therapy. Pancreas. 2018; 47(8): e55-e56, doi: 10.1097/MPA.0000000000001101, indexed in Pubmed: 30113434

105. Chatterjee S, Azad BB, Nimmagadda S. The intricate role of CXCR4 in cancer. Adv Cancer Res. 2014; 124: 31-82, doi: 10.1016/B978-0-12-4116382.00002-1, indexed in Pubmed: 25287686

106. Kratochwil C, Flechsig P, Lindner T, et al. Ga-FAPI PET/CT: tracer uptake in 28 different kinds of cancer. J Nucl Med. 2019; 60(6): 801-805, doi: 10.2967/jnumed.119.227967, indexed in Pubmed: 30954939.

107. Lapa C, Lückerath K, Rudelius M, et al. [68Ga]Pentixafor-PET/CT for imaging of chemokine receptor 4 expression in small cell lung cancer-initial experi- ence. Oncotarget. 2016; 7(8): 9288-9295, doi: 10.18632/oncotarget.7063, indexed in Pubmed: 26843617.

108. Kircher M, Herhaus P, Schottelius M, et al. CXCR4-directed theranostics in oncology and inflammation. Ann Nucl Med. 2018; 32(8): 503-511, doi: 10.1007/s12149-018-1290-8, indexed in Pubmed: 30105558.

109. Vag T, Gerngross C, Herhaus P, et al. First experience with chemokine receptor cxcr4-targeted PET imaging of patients with solid cancers. J Nucl Med. 2016; 57(5): 741-746, doi: 10.2967/jnumed.115.161034, indexed in Pubmed: 26769866

110. Schottelius M, OsI T, Poschenrieder A, et al. [Lu]pentixather: comprehensive preclinical characterization of a first cxcr4-directed endoradiotherapeutic agent. Theranostics. 2017; 7(9): 2350-2362, doi: 10.7150/thno.19119, indexed in Pubmed: 28744319.

111. Giesel FL, Kratochwil C, Lindner T, et al. Ga-FAPI PET/CT: biodistribution and preliminary dosimetry estimate of 2 DOTA-containing FAP-targeting agents in patients with various cancers. J Nucl Med. 2019; 60(3): 386-392, doi: 10.2967/jnumed.118.215913, indexed in Pubmed: 30072500 